\title{
O CAMINHO CONTRADITÓRIO DA PROFISSIONALIZAÇÃO DOCENTE PARA A NOVA GERAÇÃO UNIVERSITÁRIA
}

\author{
Glauco Ludwig Araujo ${ }^{1}$
}

\section{Resumo}

O presente artigo traz reflexões sobre o perfil dos novos professores universitários e a polêmica discussão sobre o processo de profissionalização da docência, levando em consideração especialmente as condições de trabalho e as demandas de produtividade científica. É baseado especialmente no banco de dados da pesquisa "A nova geração de professores universitários: profissionalização, condições de trabalho e sua relação com a produtividade científica na UFRGS", estudo de caso realizado na Universidade Federal do Rio Grande do Sul durante os anos de 2012 e 2013. Buscou-se revisitar os dados encontrados na pesquisa, de modo a atualizar a reflexão para o contexto atual. $O$ caráter das mudanças observadas está em consonância com o amplo movimento de transformação da universidade brasileira, acelerado especialmente na última década do século passado. A metamorfose do perfil da universidade pode ser categorizada na passagem de um caráter de instituição social para o de organização social, de princípios sociais universais para o de objetivos particularistas. Nesse contexto, os novos professores enfrentam a problemática da profissionalização, em meio às contradições de um processo em que as condições de trabalho e demandas crescentes de produtividade científica atuam no sentido inverso ao de uma maior autonomia de trabalho. Incorporam o novo ethos acadêmico mesmo em meio a dificuldades e repercussões negativas sobre o seu trabalho e vida pessoal, assimilando os valores da nova sociabilidade produtiva.

Palavras-chave: Trabalho docente universitário; Professores iniciantes; Produtividade científica; Condições de trabalho; Profissionalização docente; UFRGS.

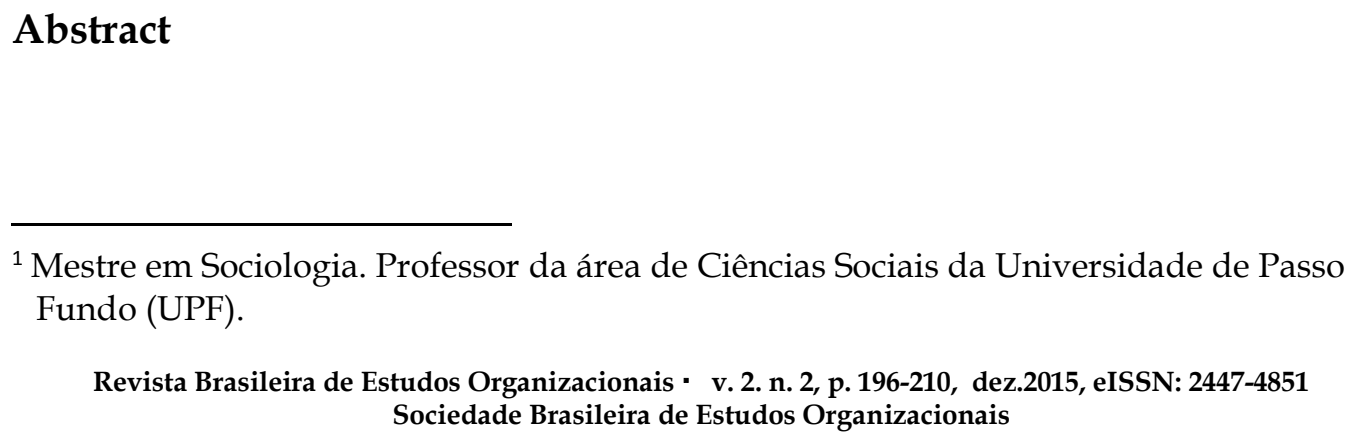

${ }^{1}$ Mestre em Sociologia. Professor da área de Ciências Sociais da Universidade de Passo Fundo (UPF). 


\section{O CAMINHO CONTRADITÓRIO DA PROFISSIONALIZAÇÃO DOCENTE PARA A NOVA GERAÇÃO UNIVERSITÁRIA \\ Glauco Ludwig Araujo}

This article reflects on the profile of the new university professors and controversial discussion about the process of professionalization of teaching, with particular consideration of working conditions and scientific productivity demands. It is based especially in the research database "The new generation of academics: professionalization, working conditions and its relation to scientific productivity in UFRGS", a case study conducted at the Federal University of Rio Grande do Sul (UFRGS) during the years of 2012 and 2013. It sought to revisit the data found in the research in order to update the reflection to the current context. The character of the changes observed is consistent with the broad movement of transformation of Brazilian university, accelerated particularly in the last decade of the last century. The metamorphosis of the university1s profile can be categorized in its change from a social institution to a social organization and from social principles to particularistic goals. In this context, new teachers face the problem of professionalization, amid the contradictions of a process in which the working conditions and scientific productivity increasing demands operate in reverse to the greater autonomy of work. They incorporate the new academic ethos even amid difficulties and negative impact on their work and personal life, assimilating the values of the new productive sociability.

Keywords: University teaching; Beginning teachers; Scientific productivity; Working conditions; Professionalization of teaching; UFRGS.

\section{Resumén}

El presente artículo trae reflexiones sobre el perfil de los nuevos profesores universitarios y a polémica discusión sobre el proceso de profesionalización de la docencia, llevando en consideración especialmente las condiones de trabajo y las demandas de productividad científica. Está fundamentado especialmente en el banco de datos de la investigación "La nueva generación de profesores universitarios: profesionalización, condiciones de trabajo y su relación con la productividad científica en la UFRGS", estudio de caso realizaod en la Universidade Federal do Rio Grande do Sul durante los años de 2012 y 2013. El studio buscó rever los datos encontrados en la investigación, de modo a actualizar la reflexión para el context actual. El carácter de los cambios observados está en consonancia con el amplio movimiento de transformación de la Universidad brasileña, acelerado en especial en la última década del siglo pasado. La metamorfosis del perfil de la Universidad puede ser categorizada por el paso de un carácter de institución social para el de organización social, de principios sociales universals para el de objetivos particularistas. En ese context, los nuevos profesores enfrentan la problemática de la profesionalización, en medio a las contradicciones de un proceso en el cual las condixiones de trabajo y 


\section{O CAMINHO CONTRADITÓRIO DA PROFISSIONALIZAÇÃO DOCENTE PARA A NOVA GERAÇÃO UNIVERSITÁRIA \\ Glauco Ludwig Araujo}

demandas crecentes de productividad científica actúan en el sentido inverso al de una mayor autonomía de trabajo. Incorporan el Nuevo ethos académico mismo en el medio a dificultades y repercusiones negativas sobre tu trabajo y vida personal, asimilando los valores de la nueva sociabilidad productiva.

Palabras clave: Trabajo doene universitario; Profesores iniciantes; Productividad científica; Condiciones de trabajo; Profesionlización docente; UFRGS.

\section{Introdução}

O presente artigo analisa o perfil dos novos professores universitários federais e a polêmica discussão sobre o processo de profissionalização da docência, levando em consideração especialmente as condições de trabalho e as demandas de produtividade científica. É baseado especialmente no banco de dados da pesquisa "A nova geração de professores universitários: profissionalização, condições de trabalho e sua relação com a produtividade científica na UFRGS", estudo de caso realizado na Universidade Federal do Rio Grande do Sul durante os anos de 2012 e 2013. Buscou-se revisitar os dados encontrados na pesquisa, de modo a atualizar a reflexão para o contexto atual.

O artigo é redigido em um cenário de crise econômica e política, no qual as universidades públicas atravessam um momento novamente difícil, com cortes de recursos e consequências sobre a atividade docente. Em que pese as entrevistas terem sido realizadas há três anos, o caráter das mudanças observadas está ainda em consonância com o amplo movimento de transformação da universidade brasileira, acelerado especialmente na última década do século passado.

\section{Mudanças Paradigmáticas do Ensino Superior no Brasil}

A análise sobre o trabalho docente universitário no Brasil tem sido realizada em diversos âmbitos. Alguns estudos acadêmicos da área da Educação trouxeram inicialmente reflexões sobre a formação identitária do professor de ensino superior. Problemáticas como o autoreconhecimento profissional de ser professor em sujeitos que também se identificam como profissionais em suas formações de origem são trazidos à tona. Fatores como a fragilidade na formação didática desses professores e suas repercussões sobre o ensino também têm sido ressaltados. Entretanto, desde meados da década de 1990 têm se ampliado razoavelmente os estudos sobre as condições de trabalho docente nesse nível de ensino.

Não parece fortuito que essa ampliação de um campo de pesquisa tenha acontecido em concomitância com certas transformações do trabalho 


\section{O CAMINHO CONTRADITÓRIO DA PROFISSIONALIZAÇÃO DOCENTE PARA A NOVA GERAÇÃO UNIVERSITÁRIA \\ Glauco Ludwig Araujo}

docente e da própria universidade brasileira. Esta carrega ainda as marcas de sua formação tardia e como "universidade conglomerada" (FERNANDES, 1975), na qual as unidades tradicionais que formaram o princípio do ensino superior no país (inspirado no modelo napoleônico) dificultaram a formação de um sistema universitário unitário. E foi a universidade um dos alvos da reforma do Estado brasileiro iniciada nos anos $1990^{2}$, em que passa a ser concebida não mais como instituição social mas como organização social, transformação que se traduz na mudança de referências sociais universais para objetivos particulares das próprias instituições e seus agentes, que entram em um "processo de competição com outras [organizações sociais] que fixaram os mesmos objetivos particulares" (CHAUÍ, 2003, p. 6).

As finalidades particularistas ganham força com o enxugamento financeiro para o setor público, pois, desde então, as instituições universitárias passam a ter o seu montante de recursos condicionados a execução de certos objetivos fixados pelo Estado. As avaliações estatais sobre as universidades ganham peso e se configuram nas afiadoras da legitimidade para o recebimento de apoio financeiro. Se por um lado, a onda avaliadora buscava superar as formas de distribuição de recursos político-clientelistas, por outro, passou a ser utilizada também como mecanismo de contenção de gastos (ARAGÓN; ROCHA, 2000). Além disso, facilita-se o acesso das universidade públicas ao financiamento privado, o que, em meio a um cenário de contingenciamento de recursos, passa a ser visto como o mecanismo mais rápido e eficiente para superar as dificuldades próprias do parco apoio recebido do Estado.

A década de 1990 foi aquela em que não só se inicia o processo de "privatização interna" das IES públicas (MANCEBO, 2010; MARTINS, 2009; SGUISSARDI; SILVA JÚNIOR, 2009), como também aquela em que mais se amplia a participação privada no ensino superior brasileiro (MANCEBO, 2010). Observa-se especialmente nos governos de Fernando Henrique Cardoso (1995-2002) o período mais favorável a expansão privada. No ano inicial do seu primeiro mandato em 1995, as matrículas privadas correspondiam a 60,2\% do total. Quando encerra seu segundo mandato em 2002, esse percentual já tinha saltado para 69,8\% (INEP, 2013). Conforme Ludwig Araujo (2013, p. 23),

\footnotetext{
Todavia, as gestões Lula da Silva não ampliaram a participação pública no total de matrículas de graduação. Lula da Silva assumiu o governo num quadro de $29,2 \%$ de matrículas em IES públicas e $70,8 \%$ em instituições particulares. Ao final do segundo mandato, as matrículas de IES públicas respondiam por $27,8 \%$ do total, frente aos $72,2 \%$ em instituições privadas. $\mathrm{O}$
}

\footnotetext{
${ }^{2}$ Sobre esse assunto, pode-se verificar o destaque dado às universidades no novo modelo de organização estatal nas teses defendidas por Luiz Carlos Bresser Pereira, ex-ministro titular do Ministério da Administração Federal e da Reforma do Estado (PEREIRA, 1996 apud SGUISSARDI; SILVA JÚNIOR, 2009, p. 34-35).
} 


\section{O CAMINHO CONTRADITÓRIO DA PROFISSIONALIZAÇÃO DOCENTE PARA A NOVA GERAÇÃO UNIVERSITÁRIA \\ Glauco Ludwig Araujo}

incentivo recente à ampliação de vagas nas IFES, por meio do programa REUNI, fez com que, nos últimos três anos de seu governo, houvesse um crescimento maior das matrículas nas IES públicas que nas privadas. Todavia, os resultados não representaram uma inflexão no percentual da participação privada no ensino superior brasileiro.

Nesse sentido, pode-se afirmar que mesmo pesando diferenças entre as políticas governamentais operadas nos períodos dos dois expresidentes, a concepção de universidade como organização social permaneceu intocada. Nas gestões petistas se observou o aumento de recursos destinados as instituições federais, mas tendo como contrapartida o atendimento a metas de expansão de vagas que não correspondem ao aporte estatal oferecido, especialmente se levarmos em consideração os déficits históricos em termos de infraestrutura e recursos humanos. É expressivo desse processo o Programa de Apoio a Planos de Reestruturação e Expansão das Universidades Federais (REUNI), em que se estabeleceu "contratos de gestão" entre o Estado e as IFES. Entretanto, o terceiro parágrafo, inciso III do artigo $3^{\circ}$, menciona que "atendimento dos planos é condicionado à capacidade orçamentária e operacional do Ministério da Educação" (BRASIL, 2007). Esse ponto é elucidativo da relação desigual que se estabelece, na qual as universidades são obrigadas a cumprirem suas metas para receberem verbas, mas o Estado permanece com o dispositivo legal de não cumprir com sua parte. E a situação justamente se torna dramática quando se observam cortes de verbas para o ensino superior, como os anunciados em 2015 pelo governo da presidente Dilma Rousseff.

Nas últimas duas décadas também se observou um crescimento exponencial da pós-graduação stricto sensu no Brasil. A partir de dados da Coordenação de Aperfeiçoamento de Pessoal de Nível Superior (CAPES), pode-se verificar que o número total de cursos oferecidos em 2010 era 3,25 vezes maior do que o oferecido até o ano de 1990 (CAPES, 2010). Essa expansão também esteve marcada pela preponderância de um sistema avaliativo que condiciona o fomento, em uma fase caracterizada pela "ênfase em publicações, valorizadas por uma hierarquia complexa e sofisticada" (CURY, 2009, X-XI). O professor que deseja atuar na pósgraduação precisa se adequar às novas diretrizes, publicando uma média anual de artigos científicos ou livros em periódicos ou editoras de prestígio, classificados pela CAPES por intermédio do sistema Qualis. E esses índices avaliativos são igualmente levados em consideração pelas agências de fomento à pesquisa.

Destarte, a pós-graduação, tal qual o restante da universidade brasileira tem passado por mudanças paradigmáticas. Se antes focada na formação de quadros docentes para o ensino superior, agora tem sua primazia na formação de pesquisadores (MORAES, 1999; KUENZER; MORAES, 2005; SAVIANI, 2006). A grande questão é que, para ser 


\section{O CAMINHO CONTRADITÓRIO DA PROFISSIONALIZAÇÃO DOCENTE PARA A NOVA GERAÇÃO UNIVERSITÁRIA \\ Glauco Ludwig Araujo}

pesquisador no Brasil, provavelmente a pessoa precisará ser também professora de ensino superior, uma vez que a esmagadora maioria dos espaços de produção científica estão localizados nas universidades públicas. Em outras palavras, as mudanças na pós-graduação não têm conseguido reverter os problemas observados quanto a formação docente para o ensino, ao passo que reforçam o âmbito da pesquisa com ênfase nos resultados quantitativos de produção. Segundo Sguissardi e Silva Júnior (2009), é por intermédio da pós-graduação que se operam as principais mudanças na universidade brasileira, trazendo como resultado a formação de um "professor dotado de uma sociabilidade produtiva" (ibidem, p.47). Processo que, como veremos, atua na modificação do ethos do professor já atuante no ensino superior, bem como na formação de uma nova geração que inicia sua trajetória profissional com os valores atuais de produtividade inculcados.

Os critérios atuais de produtividade parecem estar gerando um certo produtivismo acadêmico, entendido aqui como o "[...] fenômeno em geral derivado dos processos oficiais ou não de regulação e controle, supostamente de avaliação, que se caracteriza pela excessiva valorização da quantidade da produção científico-acadêmica, tendendo a desconsiderar a sua qualidade" (SGUISSARDI, 2010). Processo que tem trazido repercussões negativas sobre a qualidade dos "produtos científicos", bem como sobre os próprios pesquisadores, afetados por problemas de saúde física e psíquica, aumento da jornada de trabalho (em extensão e intensidade), diminuição do tempo de lazer, invasão do trabalho na esfera privada, entre outros (LUDWIG ARAUJO, 2010; SGUISSARDI; SILVA JUNIOR, 2009).

\section{A Docência na UFRGS}

A escolha pela Universidade Federal do Rio Grande do Sul para o estudo de caso se justifica por ser uma instituição considerada (a partir de vários indicadores) como uma universidade de excelência acadêmica, tendo sido apontada por dois anos seguidos (2011 e 2012) como a melhor instituição de ensino superior do país, a partir do Índice Geral de Cursos (IGC) do Ministério da Educação (MEC). Seus índices de qualificação do corpo docente estão próximos dos nacionalmente observados. E possui um conjunto de programas de pós-graduação renomados, que fazem parte do cotidiano da universidade e de suas atividades.

O percentual de novos professores também acompanha a média nacional, que atualmente é de aproximadamente um terço, em relação a dois terços de docentes das gerações anteriores. Para fins de classificação, considerou-se como "novos professores" os docentes ingressantes a partir do ano de 2004, período posterior a aprovação da Reforma da Previdência, como um momento importante a marcar as transformações do trabalho docente universitário. 


\section{O CAMINHO CONTRADITÓRIO DA PROFISSIONALIZAÇÃO DOCENTE PARA A NOVA GERAÇÃO UNIVERSITÁRIA \\ Glauco Ludwig Araujo}

A abordagem adotada foi de natureza quali-quantitativa, tendo como dados primários as entrevistas semi-estruturadas realizadas com 24 docentes da nova geração da UFRGS, bem como estatísticas obtidas junto à PróReitoria de Gestão de Pessoas (PROGESP) e nos Relatórios de Gestão da instituição (UFRGS, 2012). Esses professores foram selecionados a partir de seleção aleatória estratificada, buscando preservar ao menos uma correspondência em relação aos critérios de faixa etária e áreas do conhecimento. Desse modo, ainda que não se possa generalizar alguns achados, eles permitem estabelecer relações explicativas para fenômenos já observados em pesquisas anteriores de natureza quantitativa.

Além disso, as estatísticas obtidas nos Relatórios de Gestão da primeira década do século XXI permitem análises interessantes. Entre os anos de 2001 e 2010, as matrículas de graduação aumentaram 16,03\% e as da pós-graduação stricto sensu em 34,27\%. A pós-graduação lato sensu teve suas matrículas acrescidas em impressionantes 364,72\%. Nesse mesmo período, o aumento do quadro docente foi de apenas $7,27 \%$ e o quadro se servidores técnico-administrativos teve uma diminuição de 14,42\% (UFRGS, 2012) ${ }^{3}$.

Ao observarmos os dados estatísticos da instituição há indicadores de maiores encargos docentes, seja no âmbito do ensino ou da administração universitária. Contudo, a hipótese que trabalhamos (e que os depoimentos dos entrevistados nos permitiram confirmar) é a de que os maiores encargos estão no âmbito da pesquisa, uma parcela de trabalho nem sempre mensurável, mas que se expressa em dados objetivos (como o da extensão da jornada de trabalho) e outras repercussões que analisamos em linhas gerais na sequência do artigo.

\section{Profissionalização}

Discutir o processo de profissionalização do trabalho docente implica definições prévias em relação a certos conceitos adotados. Parte-se aqui da ideia que a categoria trabalho é central para o entendimento dos processos sociais, seja do ponto de vista das estruturas que emergem das relações sociais de trabalho, seja nas suas repercussões sobre os indivíduos. Nesse sentido, categorias como alienação e divisão social do trabalho permitem ampliar o espectro de análise sobre a emergência das profissões e o seu sentido social. Por alienação entende-se o processo pelo qual os seres humanos não controlam plenamente sua atividade produtiva e não se identificam inteiramente com o resultado do seu trabalho, que se torna alheio a sua vontade e propriedade (MARX, 2004). Já a divisão social do trabalho seria "o processo pelo qual as atividades de produção e reprodução social diferenciam-se e especializam-se, sendo

\footnotetext{
${ }^{3}$ Não foi possível analisar o impacto da terceirização sobre o quadro técnico-administrativo, pois o número de servidores nesse enquadramento só aparece nos relatórios a partir do ano de 2010.
} 


\section{O CAMINHO CONTRADITÓRIO DA PROFISSIONALIZAÇÃO DOCENTE PARA A NOVA GERAÇÃO UNIVERSITÁRIA \\ Glauco Ludwig Araujo}

desempenhadas por distintos indivíduos ou grupos" (HOLZMANN, 2011, p. 127).

No interior da divisão social do trabalho, as profissões podem ser classificadas enquanto grupos de interesse associados ao sistema de classes sociais, marcadas pela peculiaridade de suas atividades e pela propriedade de um conjunto de saberes específicos. $O$ processo de profissionalização pode ser entendido também como um projeto de mobilidade coletiva, visando preservar ou ampliar posições socioeconômicas e/ ou de prestígio social (LARSON, 1979 apud ALMEIDA, 2010, p. 124). Por essa ótica, a consolidação de uma determinada profissão se expressaria no aval social conferido àquele grupo para que exerça determinadas funções com maior legitimidade, bem como uma autonomia sobre o seu próprio trabalho maior do que para os trabalhadores "não profissionalizados". Dito de outra forma, aos grupos profissionalizados o trabalho prescrito não pesaria com a mesma força do que aos demais, abrindo espaço para o exercício criativo ampliado e para um controle sobre a forma e conteúdo do trabalho.

A questão central que se coloca é sobre a possibilidade enquadrarmos o trabalho docente universitário na atualidade dentro de um processo de profissionalização. Ao observar-se os índices de qualificação formal (medidos pela titulação do corpo docente das instituições), tem-se indicadores positivos - tanto em nível nacional como no caso estudado. No que tange os regimes de trabalho, igualmente se observam dados positivos, especialmente no aumento das funções docentes exercidas em regime de dedicação exclusiva (DE). Dentre os novos docentes, por consequência, o percentual de professores com alta titulação e em regimes de DE é ainda mais expressivo. O prestígio social pode ser observado no status diferenciado que se atribui aos professores universitários, reconhecidos como "especialistas" e demandados por outras instituições (como a mídia) para opinarem sobre diferentes assuntos, bem como na remuneração superior em relação à de professores dos outros níveis de ensino ${ }^{4}$.

No caso da formação dos novos docentes da UFRGS, observou-se um outro indicador de profissionalização: a formação também com dedicação exclusiva. Os entrevistados majoritariamente tiveram uma formação exclusivamente acadêmica, em poucos casos com experiências de trabalho extra-acadêmicas, mas de pouco tempo ou relevância. Em síntese, a vivência universitária ajudou a moldar suas escolhas profissionais e, supomos, um modo de ser professor-pesquisador. As aspirações

\footnotetext{
${ }^{4}$ Ressalte-se, contudo, que o salário dos docentes universitários foi depreciado significativamente nas últimas décadas. Dentre os professores federais, os reajustes de 2013 e 2014 superaram as inflações respectivas dos anos, mas ainda estão longe de superarem as perdas salariais históricas em decorrência da inflação (ARAUJO 2013, p. 36). Para equiparar ao salário real de 1998, seria necessário um reajuste imediato de cerca de $40 \%$, na média geral.
} 


\section{O CAMINHO CONTRADITÓRIO DA PROFISSIONALIZAÇÃO DOCENTE PARA A NOVA GERAÇÃO UNIVERSITÁRIA \\ Glauco Ludwig Araujo}

profissionais que se seguiram ao ingresso na carreira docente também se encontram circunscritas ao meio acadêmico: consolidação de grupos de pesquisa; busca de projetos; aumento de publicações; ingresso no quadro da pós-graduação; melhoria de condições de trabalho; reconhecimento; entre outras.

A aspiração por melhores condições de trabalho foi citada frequentemente. As dificuldades com a estrutura física e suporte parecem estar sendo mais sentidas pelos ingressantes, que experimentam um período de indefinições quanto ao seu lugar na universidade e os instrumentos de trabalho que pode dispor. Em que pese, obviamente, o peso diferente que esse indicador tem entre as áreas do conhecimento. Conforme Ludwig Araujo (2013, p. 77),

No caso das unidades acadêmicas com interface aplicada ao sistema produtivo tais dificuldades são minimizadas pelos projetos em parceria com empresas privadas, o que pode ser um dos fatores explicativos das disparidades estruturais visualizadas na universidade. [...] A mobilização de recursos oriundos de projetos de pesquisa possibilita melhorias no ambiente de trabalho mesmo quando não diretamente relacionada à esfera produtiva. Essa tem sido uma estratégia recorrente dos docentes para sanarem as deficiências estruturais da universidade nos seus âmbitos de atuação [...]

A baixa participação associativa em entidades reivindicatórias, como

os sindicatos, também foi observada. Os professores, na sua maioria, explicam sua não participação pelo pouco interesse na política como um todo. Mas vários ressaltaram a falta de tempo para se envolverem, em função das outras atividades que exercem. Os que afirmaram participar de movimentos paredistas, como paralisações ou greves, alegam que mesmo nesses momentos não é possível paralisar inteiramente as suas atividades (em especial as da pesquisa e pós-graduação). Certas tarefas são vistas por estes como "inadiáveis". Em certa medida, pode-se dizer que o são, se levarmos em consideração o modo de organização da produção científica e da pós-graduação atualmente existente no Brasil, bem como os mecanismos de pressão existentes sobre os docentes.

De tudo isso, vemos o quão contraditório é o processo de profissionalização docente. Por um lado, indicadores que apontam a qualificação formal em termos de formação e contratos de trabalho, por outro, demandas crescentes em âmbitos como o da pesquisa e pósgraduação, que trazem repercussões sobre a jornada de trabalho (intensidade e extensão), bem como sobre atividades fora do trabalho. Em que medida a autonomia docente como o sentido geral da profissionalização se mantém?

\section{Relação Com a Produtividade Científica}




\section{O CAMINHO CONTRADITÓRIO DA PROFISSIONALIZAÇÃO DOCENTE PARA A NOVA GERAÇÃO UNIVERSITÁRIA \\ Glauco Ludwig Araujo}

O aumento dos encargos docentes pode ser observado inicialmente na relação de números de aluno por professor nos cursos de graduação. Igualmente, na diminuição do quadro de apoio técnico-administrativo, ampliando as funções burocráticas e administrativas exercidas por professores. Entretanto, é no âmbito da pesquisa que se observa o aumento mais expressivo de encargos docentes, nem sempre fácil de estimar quantitativamente, uma vez que vários desses encargos não são computados na carga horária nominal da jornada de trabalho.

A produtividade científica é uma exigência para os professores que pretendem ser também pesquisadores, uma vez que o atendimento das metas é condição para o ingresso e permanência em programas de pósgraduação, bem como para o recebimento de financiamento de pesquisa. Dessa forma, os professores internalizam a pressão pela sociabilidade produtiva (muitas vezes produtivista), assumindo as demandas externas como suas, antecipando as consequências que sofrerão nas suas condições de trabalho caso não as atendam. Conforme uma das entrevistadas,

\footnotetext{
[...] eu tenho que produzir artigos. Eu tenho que participar de congressos também. Porque é baseado nesse perfil que os órgãos financiadores me classificam como merecedora ou não de ganhar uma bolsa de produtividade, ou o que seja. Ou uma verba para fazer uma pesquisa. Se eu não fizer isso, eu não ganho o dinheiro. Se eu não ganhar o dinheiro, eu não vou fazer pesquisa. Se eu não fizer pesquisa, eu de alguma forma vou estar me frustrando porque eu gosto de fazer essas coisas. (Entrevistada C4 - Banco de Dados da Pesquisa "A nova geração de professores universitários: profissionalização, condições de trabalho e sua relação com a produtividade científica na UFRGS").
}

A racionalização crítica desse processo, contudo, não é a regra. Diversos professores entrevistados afirmaram não enxergarem as demandas produtivas como formas de pressão negativas. Internalizam as demandas como preocupações pessoais, da vontade que possuem de fazer parte do meio acadêmico na sua plenitude, o que implica garantir sua própria produtividade. $O$ sentimento de pressão externa não os acompanha. Todavia, as entrevistas sugeriram existir uma relação entre a sensação de pressão externa e os índices de produção obtidos. Professores que mencionaram não sentirem pressões externas, em geral eram os que afirmaram também terem índices de produtividade altos, bem como preocupação pessoal elevada em relação ao atendimento das metas.

Essa atenção especial em relação aos índices repercute sobre outros agentes da vida acadêmica, em especial estudantes. Alguns entrevistados relataram que pressionam seus orientandos no sentido do cumprimento de prazos e para a publicação de artigos em co-autoria. Uma professora relatou ter se sentido mal com um orientando que atrasou os prazos e que fez uma cobrança dura, resultando na evasão do aluno. Para não se 


\section{O CAMINHO CONTRADITÓRIO DA PROFISSIONALIZAÇÃO DOCENTE PARA A NOVA GERAÇÃO UNIVERSITÁRIA \\ Glauco Ludwig Araujo}

colocar nessa situação novamente, ela afirmou selecionar orientandos que já tenham produção. Ainda sobre estudantes, em pesquisa realizada na mesma universidade, Ludwig Araujo (2010) apontou que a priorização da produtividade científica tem trazido consequências negativas sobre $\mathrm{o}$ ensino de graduação, negligenciado em relação às esferas do trabalho docente nas quais a pressão socioeconômica é maior.

\section{As Repercussões}

As percepções que se têm sobre as repercussões do trabalho docente na vida dos entrevistados foram variadas. $\mathrm{O}$ reconhecimento é uma esfera importante para a realização pessoal, mas pode atuar como um amenizador de condições de exercício laboral adversas. Alguns sintomas de que nem tudo vai bem no trabalho aparecem explicitamente e podem ser visualizados facilmente pelos sujeitos. Ocorre assim quando problemas de saúde são percebidos na conexão com a atividade produtiva. Outros são mais sutis, como as relações familiares, dificuldades de realizar atividades não vinculadas ao trabalho, possibilidade de realizar atividades de lazer, físicas e de descanso. Conforme percebido na pesquisa,

\footnotetext{
Vários entrevistados afirmaram não terem problemas de saúde relacionados ao trabalho, o que pode sugerir outras causas, mas também que essa conexão nem sempre é estabelecida. Outros admitiram as repercussões que o trabalho apresenta, como limitador do tempo para atividades físicas, por exemplo; observaram que eventualmente $o$ trabalho lhes causa ansiedade, estresse; que prejudica uma boa alimentação; mas nem sempre avaliaram como consequências de gravidade relevante. [...] Em suma, as consequências não são determinantes para limitar o tempo dedicado ao trabalho. O oposto já não é verdadeiro, como visto acima. O tempo dedicado ao trabalho é o principal limitador para a realização de atividades físicas, cuidado com a alimentação e descanso (ARAUJO, 2013, p. 70).
}

O depoimento de uma das entrevistadas é particularmente elucidativo do motor de produtividade que faz os professores nem sempre conseguirem atender adequadamente os requisitos de uma vida saudável, tornando-os mais suscetíveis a enfermidades:

[...] é um trabalho que não tem limite definidos, nem em termos de volume, nem em termos de horário. E então, acaba que se tu não tem clareza absoluta de que tem que fazer uma ginástica, um repouso, uma alimentação boa, tu vai substituindo e colando, substituindo e colando, e pensando estratégias pra dar conta desse volume enorme de trabalho que passa por abrir mão. Pelo menos no meu caso, não sei se as pessoas são fanáticas que nem eu. Mas imagino que tenha uma espécie de 


\section{O CAMINHO CONTRADITÓRIO DA PROFISSIONALIZAÇÃO DOCENTE PARA A NOVA GERAÇÃO UNIVERSITÁRIA \\ Glauco Ludwig Araujo}

um frisson, de uma fissura acadêmica, digamos assim. E aí tu vai deixando outras coisas em segundo lugar. [...] tu está tão focado, então absorto, tão fissurado, que demora pra se dar conta, demora bastante.

(Entrevistada H4 - Banco de Dados da Pesquisa "A nova geração de professores universitários: profissionalização, condições de trabalho e sua relação com a produtividade científica na UFRGS").

O controle do tempo de trabalho foi um dos temas mais controversos entre os entrevistados. Muitos trouxeram uma visão negativa, alegando dificuldades em delimitar a extensão da jornada de trabalho, que avança inclusive para a esfera privada. Mas a maioria enxerga a flexibilidade da jornada como um dos pontos positivos da atividade docente, que permite maior autonomia. Independente dos juízos de valor que se possa fazer sobre o regime de trabalho e a flexibilidade de horários, o fato observado que saltou aos olhos foi que dentre os 24 entrevistados na pesquisa, apenas 4 cumpriam o limite de 40 horas semanais previstos no estatuto de Dedicação Exclusiva, conforme podemos ver no quadro abaixo:

entrevistados

TABELA 1 - Carga horária semanal dos professores

\begin{tabular}{lc}
\hline \multicolumn{1}{c}{ Carga semanal estimada } & Freqüência \\
\hline Até 40h & 4 \\
40h a 50h & 9 \\
50h a 60h & 7 \\
mais de 60h & 3 \\
Não soube/Não respondeu & 1 \\
\hline
\end{tabular}

Fonte: Banco de Dados da Pesquisa "A nova geração de professores universitários: profissionalização, condições de trabalho e sua relação com a produtividade científica na UFRGS".

Cumpre ressaltar que essa é a carga horária estimada pelos entrevistados, uma vez que tais números não podem constar nos registros oficiais, em função da limitação de jornada da Dedicação Exclusiva. Várias implicações que essa extensão da jornada traz podem ser aventadas, seja da quantidade ampliada de trabalho não pago aos professores (para além da já defasada remuneração), seja das consequências mais amplas em relação a diminuição do tempo destinado a outras esferas que permitem uma vida mais plena de sentido e saudável.

\section{Considerações Finais}

O presente estudo se insere em um campo de investigação que tem buscado demonstrar através de dados (quantitativos e qualitativos), problemáticas que boa parte da comunidade acadêmica tem sentido. 


\section{O CAMINHO CONTRADITÓRIO DA PROFISSIONALIZAÇÃO DOCENTE PARA A NOVA GERAÇÃO UNIVERSITÁRIA \\ Glauco Ludwig Araujo}

Inúmeros estudiosos, professores e entidades sindicais tem trazido à tona reflexões sobre a produtividade científica, como aqui a temos chamado, ou produtivismo acadêmico - como outros preferem adjetivar. Muitas dessas reflexões legitimamente questionam o impacto desses regimes de produção acadêmica sobre os próprios "produtos" da atividade científica. Entre nossos entrevistados percebeu-se igualmente essa preocupação. De modo que, as próprias finalidades da universidade e da pesquisa são desvirtuadas heteronomamente.

Os impactos sobre outras dimensões da vida acadêmica e social permanecem, contudo, ainda pouco analisados. Mesmo considerando que as análises sobre a subordinação da universidade brasileira aos desígnios de forças econômicas estranhas aos fins universitários tenham se ampliado. Urge uma agenda de pesquisas que busque investigar mais a fundo os processos de inculcação dos valores morais de produtividade vigentes. Quais os mecanismos que operam para que esses valores sejam internalizados por professores? Como se constrói a legitimidade de um modelo de organização que tem trazido repercussões visíveis sobre os docentes e seu trabalho?

Essas e outras questões podem instigar a ampliação desse campo de pesquisa, mas, fundamentalmente, espera-se que se ampliem os espaços de reflexão crítica dos próprios sujeitos que estão implicados nesse processo. Para que percebam o atual modelo de organização como uma construção histórica, feita por sujeitos, e, portanto, mutável. Em especial naquilo que os tem afetado negativamente e prejudicado a realização de uma vida plena de sentido, dentro e fora do trabalho.

\section{Referências}

ALMEIDA, António José. Contributos da Sociologia para a compreensão dos processos de profissionalização. Medi@ções: Revista OnLine da Escola Superior de Educação do Instituto Politécnico de Setúbal, v. 1, n. 2, 2010. Disponível em: <http://mediacoes.ese.ips.pt>. Acesso em: 11 abr. 2012.

ARAGÓN, Virgilio Alvarez; ROCHA, Maria Zélia Borba. A educação superior latino-americana em uma encruzilhada. In: SCHMIDT, Benício Viero; OLIVEIRA, Renato de; ARAGÓN, Virgilio Alvarez. Entre escombros e alternativas: ensino superior na América-Latina. Brasília: Editora UnB, 2000.

BRASIL. Decreto $\mathbf{n}^{\mathbf{0}}$ 6.096, de 24 de abril de 2007. Disponível em: <http://www.planalto.gov.br/ccivil_03/_Ato20072010/2007/Decreto/D6096.htm>. Acesso em: 13 dez. 2011. 
CAPES. Plano Nacional de Pós-Graduação - PNPG 2011-2020. Brasília: CAPES, 2010.

CHAUÍ, Marilena. A universidade pública sob nova perspectiva. Revista Brasileira de Educação, Rio de Janeiro, n. 24, dez. 2003. Disponível em: < http://www.scielo.br/pdf/rbedu/n24/n24a02.pdf $>$. Acesso em: 17 ago. 2012.

CURY, Carlos Roberto Jamil. Da crítica à avaliação à avaliação crítica. In: BIANCHETTI, Lucídio; SGUISSARDI, Valdemar (orgs.). Dilemas da pósgraduação: gestão e avaliação. Campinas: Autores Associados, 2009.

FERNANDES, Florestan. Universidade brasileira: reforma ou revolução? São Paulo: Alfa-Omega, 1975.

HOLZMANN, Lorena. Divisão Social do Trabalho. In: CATTANI, Antonio David \& HOLZMANN, Lorena. Dicionário de Trabalho e Tecnologia. Porto Alegre: Zouk, 2011.

INEP. Sinopses Estatísticas da Educação Superior. Disponível em: <http://portal.inep.gov.br/superior-censosuperior-sinopse>. Acesso em: 02 fev. 2013.

KUENZER, Acacia Zeneida \& MORAES, Maria Célia Marcondes de. Temas e tramas da pós-graduação em educação. Educação e Sociedade, Campinas, v. 26, n. 93, 2005.

LUDWIG ARAUJO, Glauco. Produtivismo científico, condições de trabalho docente e o ensino de graduação: transformações em curso na UFRGS. Monografia, UFRGS, 2010. Disponível em:

<http:/ / www.bibliotecadigital.ufrgs.br/ da.php?nrb=000781356\&loc $=2011$ \&l=f0de6d7038c49399 >. Acesso em: 21 dez. 2010.

A nova geração de professores universitários: profissionalização, condições de trabalho e sua relação com a produtividade científica na UFRGS. Dissertação, UFRGS, 2013. Disponível em:

https://www.lume.ufrgs.br/bitstream/handle/10183/96171/000915028. pdf?sequence=1. Acesso em: 24 nov. 2015

MANCEBO, Deise. Trabalho docente na educação superior brasileira: mercantilização das relações e heteronomia acadêmica. Revista Portuguesa de Educação [en línea] 2010, vol. 23 Disponível em: 
<http://www.redalyc.org/src/inicio/ArtPdfRed.jsp?iCve=37417086004 $>$. Acesso em: 13 dez. 2011.

MARTINS, Lucinéia Scremin. A identidade política dos professores das universidades públicas federais e as transformações no mundo do trabalho. Tese (Doutorado), UFG, 2009.

MARX, Karl. Manuscritos econômico-filosóficos. São Paulo: Boitempo, 2004.

MORAES, Maria Célia Marcondes de. Paradigmas e adesões: temas para pensar a teoria e a prática em educação. Perspectiva, Florianópolis, NUP/CED/UFSC, v. 17, n. 31, jul/dez, 1999.

SAVIANI, Dermeval. A pós-graduação em educação no Brasil: pensando o problema da orientação. In: BIANCHETTI, Lucídio \& MACHADO, Ana Maria Netto (orgs.). Bússola do escrever: desafios e estratégias na orientação de teses e dissertações. São Paulo: Cortez, 2006.

SGUISSARDI, Valdemar. Produtivismo acadêmico. In: OLIVEIRA, D.A.; DUARTE, A.M.C.; VIEIRA, L.M.F. DICIONÁRIO: trabalho, profissão e condição docente. Belo Horizonte: UFMG/Faculdade de Educação, 2010. CDROM

;; SILVA JÚNIOR, João dos Reis. Trabalho intensificado nas

Federais: pós-graduação e produtivismo acadêmico. São Paulo: Xamã, 2009.

UNIVERSIDADE FEDERAL DO RIO GRANDE DO SUL. Site oficial. Disponível em: <http:// www.ufrgs.br/> Acesso em: 19 dez. 2012. 